\title{
Health Insurance Reimbursement
}

National Cancer Institute

\section{Source}

National Cancer Institute. Health Insurance Reimbursement. NCI Thesaurus. Code C16746.

Money paid out by an insurance company to an individual, or their designated recipient, for covered medical expenses. 